\title{
Assessment Support as Part of Teacher Duties in the Subject of Swedish at the Elementary Level
}

\author{
Linda Fälth and Thomas Nordström \\ Linnaéus University \\ Växjö, Sweden \\ Ulrika B. Andersson and Stefan Gustafson \\ Linköping University \\ Linköping, Sweden
}

\begin{abstract}
The aim of this study was to examine and describe the use of a formative assessment support regarding reading instruction in grades 13 , viewed from a teacher perspective. Sixty-five teachers from all parts of Sweden responded to a questionnaire, who had used the support for at least one year. Of the participant teachers, nine were interviewed for the purpose of performing an in-depth analysis of the questions. The teachers stated that the primary use of the assessment results was to identify students in need of extra support, as a basis for performance appraisals, as well as for further lesson planning. Formative assessment was, on the one hand, described as a concrete practical method and, on the other hand, as an attitude. The results also indicate a feeling of frustration that, notwithstanding the current deeper insight into what every student needs, the teaching still proceeds on some middle-ground path or level.
\end{abstract}

Keywords: formative assessment; teachers' perspective; reading instruction; Data-based Decision Making.

\section{Introduction}

The concept of formative assessment is frequently described in the school debate as a bridge between teaching and learning. It has emerged, however, that it has not been an easy matter for teachers to implement the method (Black \& Wiliam, 2009). Furthermore, there is a lack of knowledge about how to support teachers in the implementation (Schneider \& Randel, 2010; Wiliam, 2010). Hence, we need to know more about what teachers do and what knowledge and abilities they apply when doing so. Assessment research is directed towards a variety of study objects, as illustrated in an overview by Forsberg and Lindberg (2010). The major part $(50 \%)$ of the studies published relate to student performance and 
school results, together with those concerning teachers' didactic assessment practice. Further study objects found in Swedish assessment research by Forsberg and Lindberg (ibid 2010) include school management and work, assessments as phenomena, students' experiences and perceptions of assessment, as well as the quality of assessment tools. The need for improving assessment culture should be viewed in relation to the great within- and between-school differences in student results. In connection with assessment support for grades 1-3, which applies to the participants of this study, the mapping of student reading abilities also provides recommendations based on the curriculum goals for Grade 3.

The way assessments are carried out in the classroom may affect the individual student's attitude to learning. The assessment data based on the information and on any identified gaps can function as feedback to teachers and students for adapting teaching and learning. These data may also contain valuable information to school leaders with regard to quality work and resource allocation. Besides teachers, who form the majority of the participants in the study, it also comprises school leaders, all of whom have used the same assessment tool for reading development (LegiLexi) in the elementary stage (grades 1-3). In addition to individual mapping of various reading-related abilities, this material contains recommendations to teachers for continued work with each student involving a type of assessment support. The aim of this study is to examine how the results of this assessment support are used and whether or how this affects teachers continued work in the class.

Formative assessment is a tool for learning aimed at both students and teachers, which highlights forward-looking assessment aspects focusing on students' self-regulatory ability to respond to feedback from a teacher (Black \& Wiliam, 2009; Heitink et al., 2016). In educational research, formative assessment initially focused on the design of diagnostic tests and student analyses for mapping students' cognitive positions as a starting point for teachers' planning (Black \& Wiliam, 2009; Box, 2019). Subsequently, the focus lay on clarifying learning goals to students and on creating classroom situations showing students' standing vis-à-vis these goals. Feedback from teacher to student, between students, and individual students' assessments of their own progress towards the goals are supposed to improve learning. The strength of formative assessment thus lies in that clarifying the goals and the roads leading to them is also intended to contribute to developing educational practice and attitudes to learning (Black \& Wiliam, 2009). Consequently, formative methods focus on the gap to be filled between what students currently know and what they are expected to know, according to the goals. By using the current assessment support, the teachers participating in the study received guidance about what this individual student gap could be filled with. There are critics who maintain that the concept of formative assessment is not sufficiently well defined in terms of what tools and practices are actually referred to. As the character of school subjects differs, more research is required on how various types of formative assessment will affect different subjects (Bennett, 2011; Dunn, Karee \& Mulvenon, 2009; Kingston \& Nash, 2011).

Due to the fairly one-sided focus of formative assessment studies on how students will proceed in the learning process, feedback to students, peer 
assessment and self-assessment have dominated in both international and national research in the field (Borko, Koellner, \& Jacobs, 2014; Tait-Mccutcheon \& Drake, 2016). This implies that students' own responsibility for their continued learned has received the greatest attention. As those involved in this study are grade 1-3 students, the focus of the assessment does not primarily lie on their responsibility for learning but on that of the teachers. What several studies have omitted to consider is that it is the teacher who is responsible for designing a teaching practice matching what students are required to learn in a specific school context (Dylan \& Thompson, 2008; Harlen, 2005; Wiliam, 2011). Research on how teachers' assessments and conclusions of students' cognitive development relate to didactic decisions is limited (Dylan \& Thompson, 2008; Wiliam, 2011). The didactic perspective of the present study emphasizes the importance of the use of assessments (cf. Newton, 2007). Formative assessment practice entails that teachers in their didactic work recurrently study where students find themselves cognitively and that they utilize that information to adapt their teaching to the specific school context (Dylan \& Thompson, 2008; Hattie \& Timperley, 2007), which in our study is the teaching of Swedish on the elementary level of compulsory school (grades 1-3).

\section{Data-based decision making}

A similar method for forward-looking assessment is Data-based Decision Making (DBDM), which may be defined as a systematic analysis of student data, the results of which are used for teaching adaptation (Schildkamp \& Kuiper, 2010; Schildkamp, Smit, \& Blossing, 2019). Some studies indicate that DBDM may lead to improving student performances (Carlson, Borman, \& Robinson, 2011; Lai et al., 2014). DBDM is applied on school, classroom and student levels. On the school level, principals may, for example, use DBDM in school quality work. This assessment support, which can give relevant information before decision-making on individual students' education requirements, comprises several steps:

1. Creating a clear aim for the use of the collected material. In the present study, this corresponds to assessments of students' reading abilities for the purpose of helping the teacher to determine how to proceed with the teaching.

2. Analyzing the collected material to identify learning problems and specific needs in relation to the goals. In this study, it means that the analyses of the assessed abilities should be related to the knowledge requirements of each grade.

3. Interpreting the collected material to identify possible measures and investments to improve students' learning situation. In the present study, the current assessment support also comprises recommendations on which teachers may base their teaching planning.

4. Taking measures to improve student learning. The teacher may use the teaching recommendations as a starting point for taking further measures. 
5. Evaluating the results of these measures. The cyclic recurrence of the assessment support in the study makes the evaluation of results possible (Van der Kleij et al., 2015).

These steps may result in a new collection of data, which creates a feedback circuit transforming DBDM into a cyclic iterative process (Dunn et al., 2013; Van der Kleij et al., 2015). Despite the scarcity of national research, the phenomenon of documentation and assessment seems to have grown in education systems in recent years (Jankowski et al., 2018). In a study by Blomqvist, Lindberg and Skar (2016), three teacher teams discuss student writing and the teaching of writing within the subject of Swedish on the upper secondary level. The theoretical perspective of these talks is didactic, focusing on how teachers formulate and utilize assessment information on student writing when making decisions about the contents of teaching writing. The results show that teacher assessments of student writing include several and to some extent different aspects of writing ability from what their subsequent didactic decision comprises and also that teachers have difficulty in utilizing all the available assessment data when planning their teaching. International research confirms these difficulties experienced by teachers on the classroom level (Schildkamp \& Kuiper, 2010; Schildkamp \& Teddlie, 2008). There are several factors (such as organization and teacher competence) that may enable or prevent a successful usage of collected information (tests, screenings etc.) involving data used formatively to improve teaching and learning. No comprehensive systematic studies of DBDM on the classroom level have been published in Sweden so far.

\section{Assessment support in the study}

When choosing assessment support, two important aspects of the reliability of student assessment must be considered, one being the reliability of teacher assessment, and the other whether teachers have a sufficient basis for drawing valid conclusions about student performance (Brookhart, 2009; Ercikan \& Oliveri, 2016). Research has provided us with evidence of successful educational reading instruction (Cunningham \& O'Donnell, 2015; Torgesen, et al., 2001). However, much remains to be known about how teachers make use of detailed information about student reading development and how they use that information. The formative assessment support used in the present study (Legilexi) is a Swedish assessment and instruction program, free of charge for schools, with the aim of developing all students reading ability. Furthermore, this assessment support has been explicitly designed together with researchers in connection with the mapping of student abilities so as to provide teaching recommendations on the basis of the curriculum goals for Grade 3. Both the assessment material (the tests) and the teaching recommendations are founded on 'The simple view of reading' (SVR) (Tunmer \& Gough, 1986). Following SVR, various abilities have been identified within each field (reading ability, decoding, and language comprehension), on the basis of which nine tests have been developed for assessing how far students have reached in each ability (www.legilexi.org). 


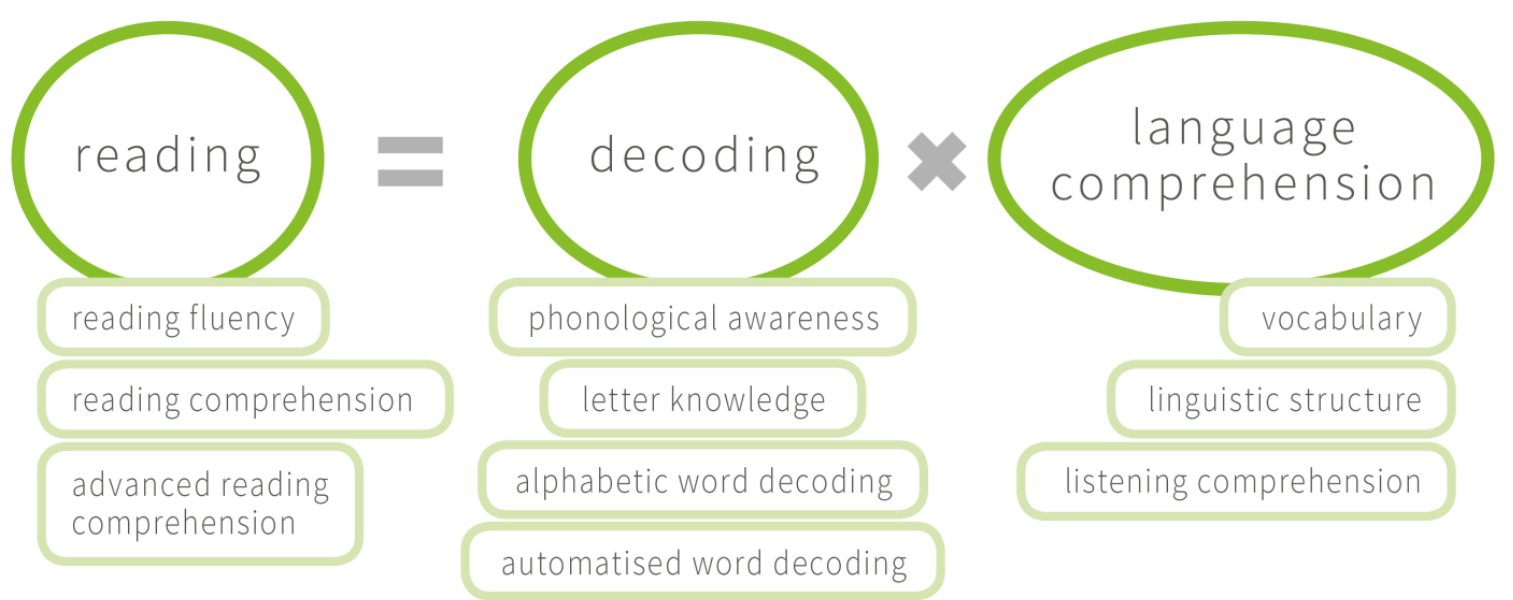

Figure 1. Illustration of abilities mapped by the LegiLexi assessment support (www.legilexi.org).

The tests are done either via Ipad or on paper. When the class has performed the assessment support tests, the teacher will gain access to students' individual results as well as to an overview of the class in the form of reading profiles. The result from each test is transformed by the tool to a level (on a 1-6 scale, with level 6 representing performances above the curriculum goals for Grade 3). It is the lowest level achieved by students on the subtests that forms the overarching level of the major areas (reading ability, decoding, and language comprehension). The current assessment tool is related to the performance levels for grades 1, 2 and 3, and the students are assessed in relation to goal levels in line with Lgr-11 (The compulsory school curriculum, Swedish National Agency for Education, 2017). Visual representations of reading development over time are available as well as information on the relation between current performance and expected Grade 3 goals. The colours of the result overview indicate that the student has a command of the tested ability and has attained the goals for the relevant grade, with green indicating that the student is well on the way to attaining the grade goals, and yellow or orange which indicates that the student still has some way to go before reaching the goals. Assessments are made three times every school year (in August, December and May) in each of the first three grades (1-3) of the compulsory school. Using the assessment support helps teachers in relating their interpretation of student results to the goals of the curriculum.

To each student profile generated from the tests (assessments) are added recommendations for further training of a specific reading ability to enable the teacher, immediately on carrying out the assessments and analyzing the results, to adapt the teaching. For example, students who have failed to attain an automatized decoding ability are primarily, but not solely, recommended to train that very component. The exercises per se do not constitute complete lessons but a supplement. 


\section{Aim and research question}

The aim of the study is to examine and describe the use of formative assessment support in teaching reading in grades 1-3, viewed from a teacher perspective. The study investigates the use of a specific assessment support (LegiLexi) on the basis of the individual teacher's views. The overarching questions to be asked are, in relation to the aim: How do teachers perceive and talk about assessment support and how do they use the results generated on student and grade levels?

\section{Method}

This section describes the design and methodology used in this study. 65 teachers participated in a questionnaire whereof nine of them took part in a supplementary interview. The questionnaire and the interviews are described followed by the analysis process.

\section{Participants and sampling}

The invitation to take part in a questionnaire containing questions with fixed answer alternatives was disseminated to all teachers using Legilexi during the 2017/2018 school year. The questionnaire, which was posted on the homepage (www.legilexi.org), remained open for five weeks. Sixty-five teachers from schools using LegiLexi responded. Even though LegiLexi is used in many more schools and also by more than one teacher at each school, these 65 teachers represented 65 different schools. All the respondents had used this formative assessment support for at least one year. Fifteen respondents were then randomly selected by lottery and asked about participating in a supplementary interview. Nine teachers who represent an equal number of schools from all over the country consented.

\section{Questionnaire and interview}

Within the framework of this study, a questionnaire was constructed comprising five different parts linked to the LegiLexi assessment too. The questionnaire was focusing on how the results of mapping student abilities were utilized. Five different statements related to this were included in the questionnaire, to each of which the respondents graded themselves on a scale from 1 to 6 , where $1=$ "not agreeing at all" and $6=$ "agreeing very much". These were the statements for the respondents to consider:

- I use the collected results when planning lessons.

- I use the results from LegiLexi as a basis for my performance appraisals.

- The results I collect are used to identify students who need special support.

- The results are used as key performance indicators for school quality work, where they are analyzed by the principal or the equivalent person.

- The results we collect are used in collegial learning in school.

In the result section, each questionnaire statement is presented separately. As the answer alternatives in the questionnaire were fixed, a follow-up interview was conducted to enable the teachers to elaborate on the answers. The interview was made individually by telephone with the overarching question as a starting point: "How do you as a teacher use the results generated in the assessment 
support?" The respondents were requested to link their answers to each one of the five question areas: lesson planning, performance appraisals, identifying students in need of extra support, key performance indicators for school quality work, and collegial learning. As the structure of the interview was open without any fixed follow-up questions, the respondents were encouraged to talk freely from their own experiences with the focus on the question heading. The interviewer requested clarification and examples only in cases where this was necessary to obtain an understanding of what the interviewee wanted to communicate. The telephone interviews, which lasted between 35 and 65 minutes, were recorded and transcribed.

\section{Analysis}

The answers to the questionnaire have been compiled in bar graphs presenting them question by question. All answers are included. The interview answers are presented in connection with each questionnaire question. They embrace anything ranging from concrete descriptions of what teachers claimed to have actually taught to their reflections about the teaching. The analysis of the interview answers focused both on statements of a similar character and on perceptions that were totally contrary to one another. The purpose was to systematize similar statements from the interview extracts in a so-called qualitative content analysis (Hsieh \& Shannon, 2005). The focus of this analysis lies on language communication with special emphasis on contents and meaning. The collected material has been approached holistically, which entails that no detailed analyses have been made of whether individuals change or hold on to their argumentation from one part of the interview to another.

The quotations are chosen to reflect the variety of the answers to each statement. All the respondents are represented in the quotes. Answers whose contents are identical, or very close to each other, have been omitted to make the presentation of the results more readable. Speech-like utterances like humming and brief pauses have been left out.

\section{Results and Analysis}

The results have been divided into five sub headings and are first presented by a graph based on the questionnaire answers to the overarching question: What uses have been made of the results of the mapping of student abilities? In relation to this question, the respondents took five different statements into consideration by grading themselves on a scale from 1 to 6 , where $1=$ "not agreeing at all", and $6=$ "agreeing very much". Under each graph there is a brief description of the contents, followed by quotations from the interviews with the teachers. Each numbered quotation introduces a new respondent. 


\section{Lesson planning}

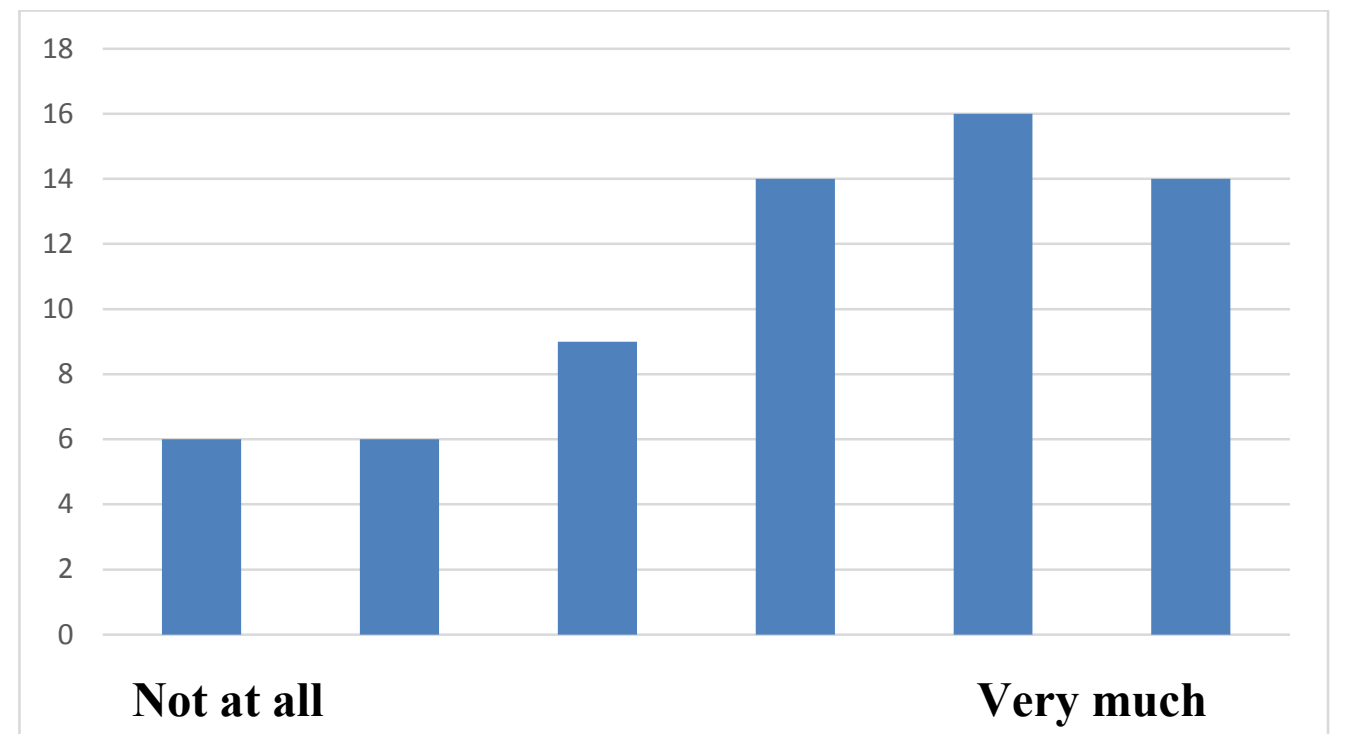

Figure 2. The results to the question how the assessments are used in lesson planning. Bars represent number of responders for each scale level.

The graph shows that 44 out of a total of 65 participant teachers have chosen to grade their use of the results for lesson planning by 4,5 or 6 , which means that they assess their own use of these results for this purpose as extensive. It also shows that 21 of the 65 teachers have graded the question by 1, 2 or 3; in other words, their use of the results for lesson planning is very small or none at all.

Teachers describe how their professional competence is challenged in their attempt to individualize and involve students in forming their own continued learning process. The support received by the teachers in the form of recommendations for each student's progress is used as a starting point for their own lesson planning, which is time-saving for the teacher.

(1) Then it is in lesson planning and individual adaptation that my knowledge as a teacher is really challenged as I also try to involve the students in planning the individual work. LegiLexi is no Quick Fix with complete solutions for my class, but the recommendations I receive make me get on with the work quickly.

The students can also be expected to benefit from the time-saving described by the teacher, as they can be offered individual formative feedback, which means that their development can proceed without interruption (Dunn et al., 2013). It also gives the teachers more chances to use their time to follow up the feedback given to the students instead of spending valuable teaching time on, for instance, analyzing and reflecting on their test results. Teachers refer to formative assessment as their own time - part three - while the previous two parts consist of made assessments (tests, author's remark) and the recommendations the teachers receive from LegiLexi. As in the DBDM work process (Van der Kleij et al., 2015), the teachers in the present study describe how their work proceeds in a number of steps. The first two steps, in their view, form a starting port for the formative work. 
(2)It is only in step three, when I have both carried out all the assessments and taken part of the recommendations in the assessment support that the formative work starts for real, I feel.

Study participants emphasize that assessment tools aiming at facilitating knowledge assessment in the classroom do not replace the teachers' own education and experience, which are, in their view, rather a prerequisite for being able to interpret and utilize the results and recommendations given. Statements like these stresses the importance of the autonomy (Timperley \& Alton-Lee, 2008) and ability of teachers to decide, on the basis of the recommendations given, what is reasonable and doable in the context shared by teacher and student. The participant teachers assert the importance of possessing both theoretical and practical knowledge to be able in situations like this to assume responsibility and make decisions about their teaching, independently of what assessment tools have been used. Their statements also show that the assessment tool can support teachers with less experience of their own in developing a formative assessment practice.

(3)To begin practice and formative teaching for real requires a lot more from me than to be able to use Legilexi or any assessment tool, for that matter. I must have good theoretical and practical knowledge to manage this.

(4)I must say that, for my part, I needed a tool like this to help me get a real start with a formative way of working and to think formatively as soon as I got the assessment tools in my hands.

The teachers look upon the assessment tool as everyday support in interpreting student test results (analysis) but also in working formatively with the recommendations based on individual test results. The results also show that they perceive the practical use of tests with the appurtenant formative recommendations as continuing professional development both with regard to teacher attitudes and to planning their own teaching. This is seen as a sign that assessment is moving in the direction of data-based decision-making (Schildkamp \& Kuiper, 2010). Teachers are given useful help with identifying their students' knowledge and with the recommendations for further work, which leads to both satisfaction and security but may also create teacher frustration, as this knowledge about students may be thought difficult to apply in practical classroom work.

(5)To begin with, I relied too much on the recommendations I got, especially regarding the students who need a lot of support in Swedish. But by now (one year later, author's remark) I feel secure in how to face these students and plan my teaching.

(6)What troubles me is that we, or I, haven't done better with individualization, now that I have more or less iron control of where the students are standing. I'd like to get away from the idea 
that teaching takes place somewhere on a middle-ground level where I don't actually have very many of my students.

New knowledge of class demands inspires teachers to individualize their teaching more than before, which requires other knowledge and possibilities than what can be directly linked to learning reading on the individual level. Other essential components that can be coupled to young students' reading development concern organizational issues, both in the classroom and on the school level.

\section{Bases for parent-teacher conference}

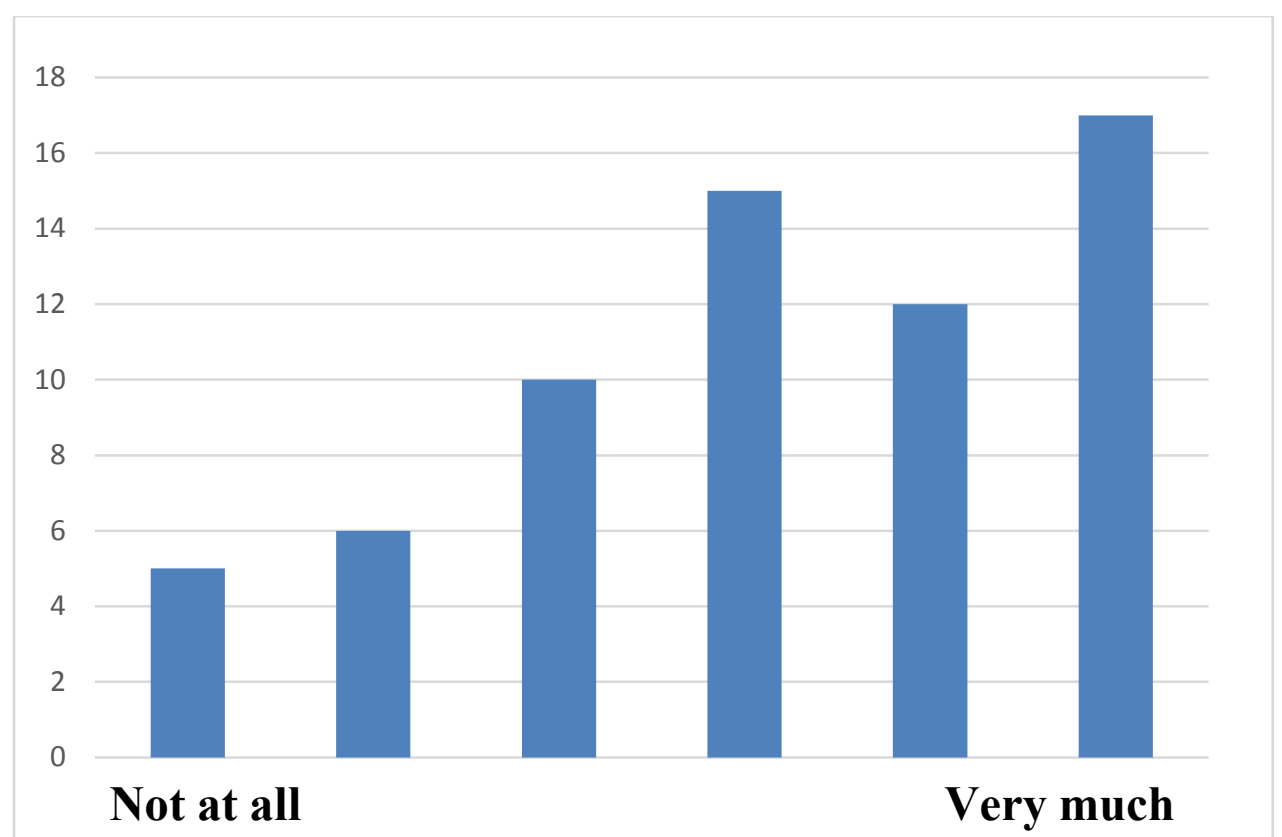

Figure 3. Results of the question whether assessments are used a basis for parent-teacher conference. Bars represent number of responders for each scale level.

The graph illustrates that 60 out of the 65 teachers participating in the study claim that the assessment support is used as a basis for performance appraisals, most of whom estimate that they use it very much. 1/3 of the participant teachers answer that they do not at all, or to a lesser extent, use the assessment support for this purpose.

In the interviews, teachers mention several reasons for using the assessment support as a basis for performance appraisals. To begin with, it contributes to focusing on selected aspects of students' reading development and/or perception of reading by visualizing selected abilities or perceptions. It also emerges that the assessment support can contribute to increasing students' participation in the actual appraisal talk. The teachers in the study draw clear parallels between the quality of the performance appraisal, on the one hand, and preparations together with the student, on the other. The assessment support 
also visualizes and follows up student knowledge development and evaluates the work proposed in previous action plans (cf. Lai et al., 2014).

(7)Nowadays, I always show parts of the students' profiles when I have my performance appraisals. Especially when I have actually had time to sit down with the student first and sort of checked off ... before the parents come - hopefully the students take more part in the talk then and I feel that there has been some development since we started to use this support for our assessment.

(8)We use this as a basis in the performance appraisal when we formulate our action plan; it also works well to use this material to show what has happened since last time.

The teachers in the study maintain that the assessment support contributes by visualizing student profiles from a theoretical perspective. The results also show that the participant teachers use it to clarify their school work on a concrete and practical level for parents with the help of the recommendations given.

(9)During a performance appraisal I can show the parent parts of the profile as well as going into what we are doing to boost the student and then I bring in examples from the recommendations that LegiLexi suggests. This makes things clear.

(10)I have got other material that I find more suitable to use in performance appraisals.

The result is permeated by the teachers' commitment and their insistence that the material they use as a basis for their performance appraisal is adapted to the purpose having parent-teacher conference.

\section{Identifying students in need of extra support}

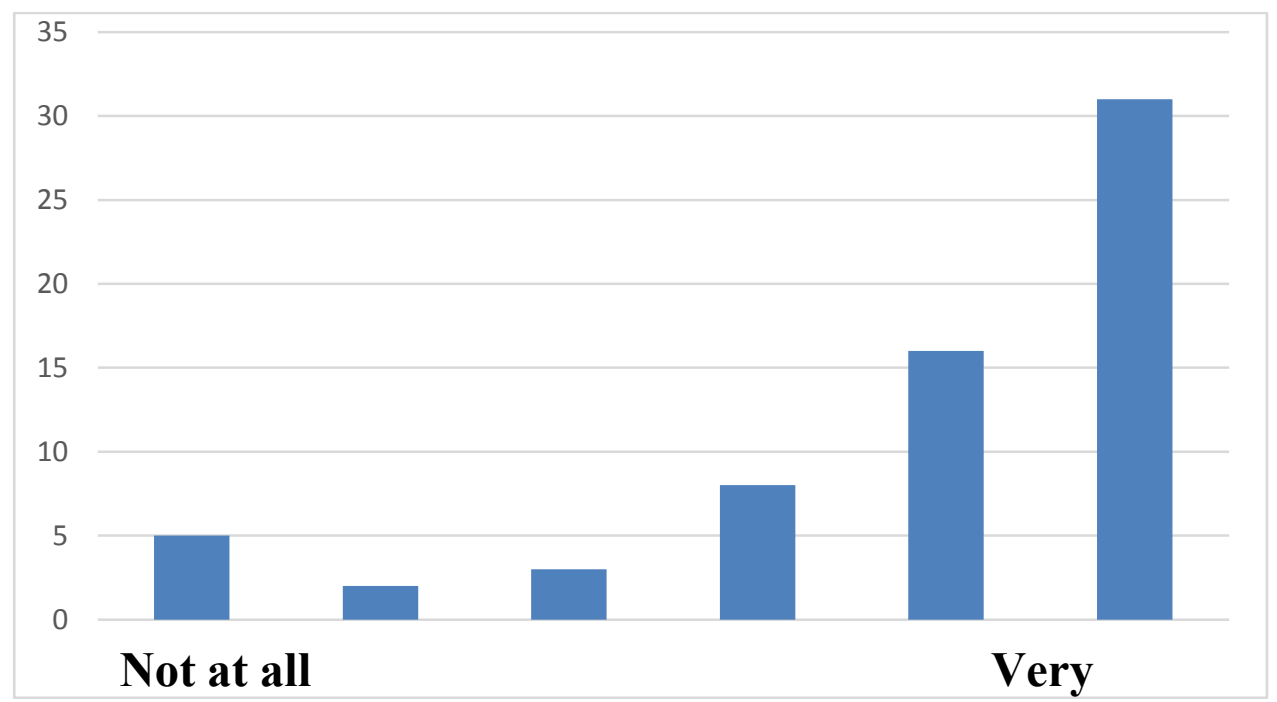

Figure 4. Results of the question whether assessments are used to identify students in need of extra support. Bars represent number of responders for each scale level. 
The graph shows that 60 out of 65 respondents state that they use the assessment support to identify students in need of extra support, 31 of whom claim that they do so very much. Five teachers do not use the assessment support for this purpose.

The interview answers confirm that teachers use the assessment support to a large extent to identify students in need of extra support, but they also claim having started to pay attention to high performance students, in other words, those who find themselves at the other end of the scale. The division of this assessment support into various subparts facilitates continued work, according to some teachers.

(11)To begin with, I mean sort of the whole of the first half year; this took a lot of time. I then thought that I should run this program with the students I was concerned about and who I knew had problems even before we got started ... but now about three semesters later I can tell you that this way of working functions very well with me as a teacher plus that I hope and actually believe that it has meant a lot to my students. Especially for those who need a little extra I can now pinpoint WHAT it is they need to train extra on ... Swedish can otherwise seem an enormously big subject and maybe hard to break down into smaller parts and by this I don't mean that the aim should be to identify students in need of extra support but that is a part of it all, isn't it.

(12)I have also become aware that there is a bunch of students that even in grade 2 reach the highest level (above the target level for grade 2 , author's remark) and those have really been identified now. Then remains the pedagogical issue of how we go on from here in our teaching. It is important not to stop at the test result; no students will benefit from knowing what marks they got on this or that test ... what I need to work with from now on is a much more important matter.

(13)This material says more about the standing of my whole class than about those who need extra support. It is rather a question of identifying what further efforts are required. 


\section{School quality work}

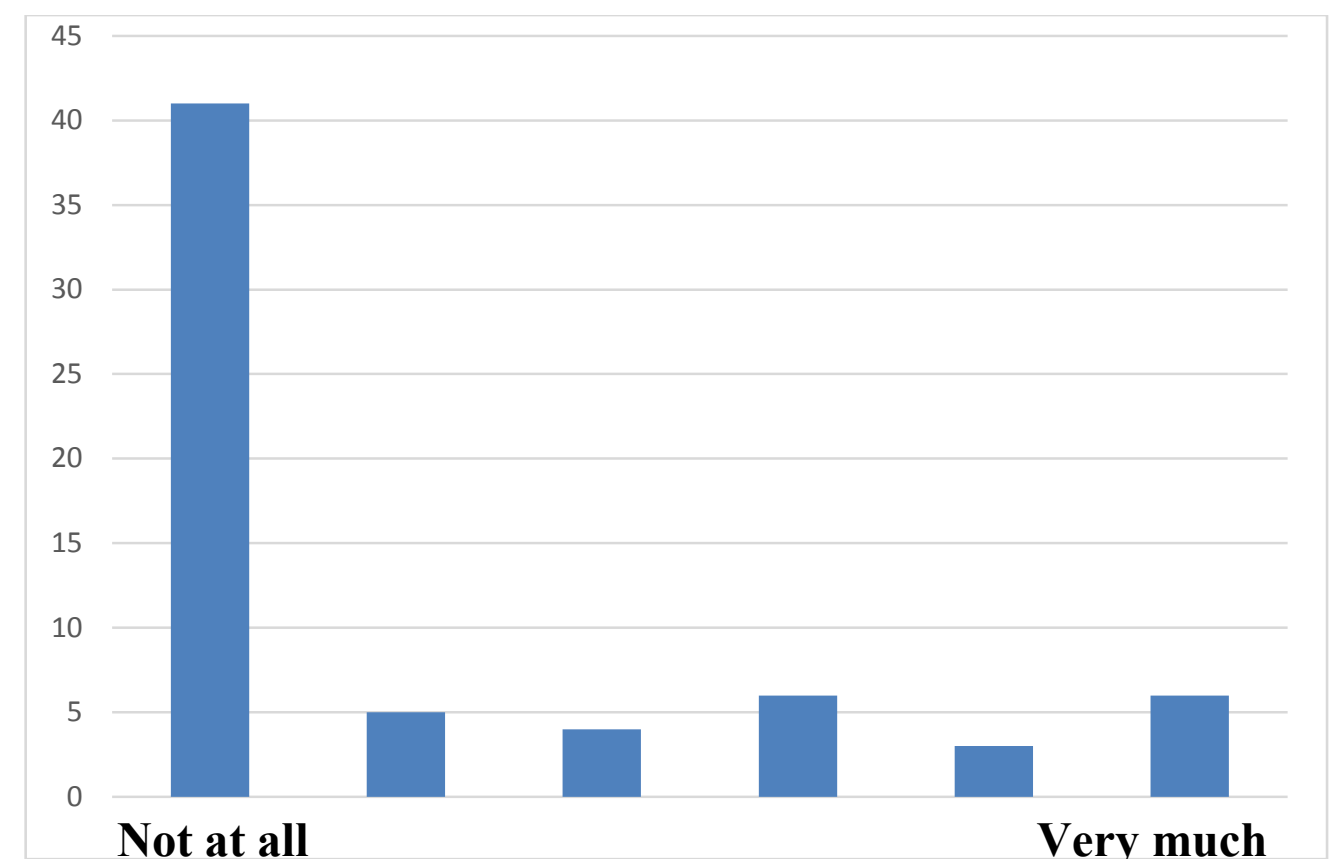

Figure 5. Results of the question whether assessments are used in school quality work. Bars represent number of responders for each scale level.

The graph shows that 41 out of 65 state that they do not use LegiLexi in the work with producing key performance indicators for school quality work.

The interview responses show that some teachers believe that using Legilexi in school quality work may become reality later on. Presently, there is however an overwhelming majority who state that it is not at all used as a key performance indicator for quality work in school.

(14)The principal demands a grade-level compilation of how the classes stand ... which he then uses when he talks about resource allocation ... he is sort of the principal of several different units here.

(15)I have seen our grade-level compilations in our school's annual quality report

(16)The first year when we compiled the results and I was able to make a comparison between several classes, it became evident that where we had thought the most resources would be needed was not at all as bad as in another class where there had been no signals upwards that they needed extra resources ... this gave rise to discussions ...

(17)It should perhaps be included as a quality basis among others, but it isn't, I know. 


\section{Collegial learning}

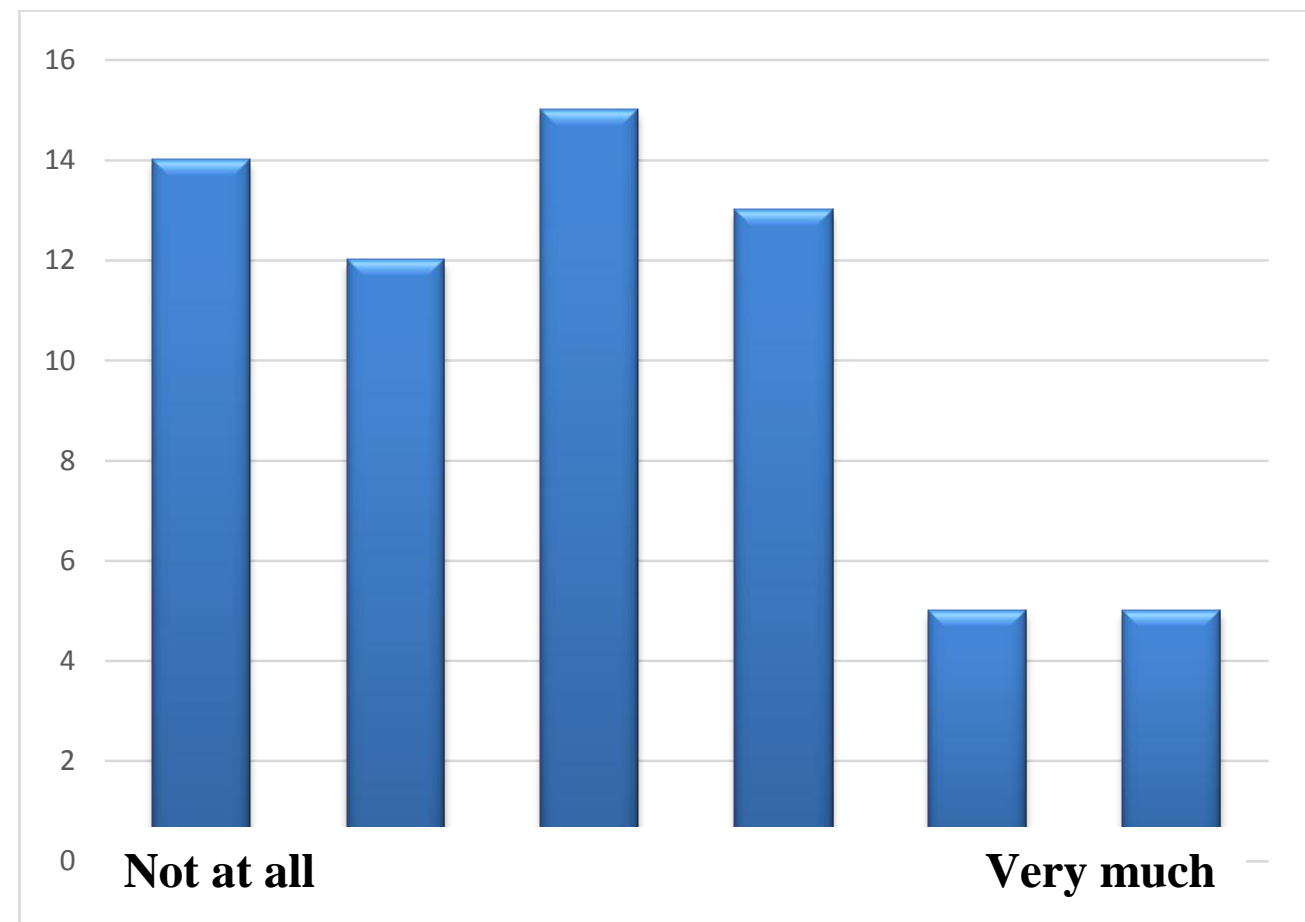

Figure 6. Results of the question whether assessments are used in collegial learning. Bars represent number of responders for each scale level.

If there are several teachers in the school or work team who use LegiLexi, collegial learning is highlighted as something that this assessment tool has contributed to developing. Teachers need opportunities within and outside their classrooms and schools to socially and collectively construct individual and joint knowledge and competence (Edwards, 2012; Li, 2019).

(18)When there were more of us who got started with using LegiLexi I felt that collegial talks and learning from each other increased ... during my years in the elementary school I never experienced that we were able to talk and thus learn from each other ... without working with concrete student cases .. I mean that we have sort of upped our talks one level ...

(19)The very best thing about this is that the whole work team today thinks roughly the same about assessments and follow-ups and work methods in Swedish as a school subject. It has become so much simpler to cooperate about students and about lesson planning ... that's what I think anyway.

(20)We talk a lot about how we can support each other now that several of us experience that, even if we now know pretty exactly where the students are standing in various fields linked to reading, the teaching still stays on a middle-ground level that is thought to suit - if not everybody, at least most of them. This makes me so frustrated. 
(21)I just say I'm sorry ... I didn't get any other colleagues to join me on the trip, so there is hardly any collegial learning taking place in this very place.

\section{Discussion}

The results of this study show that data generated from using the current assessment support gives information to teachers both on individual and on class levels. The participant teachers state that the results are primarily used to identify students in need of extra support, as a basis for performance appraisals, and for further lesson planning. The interviewees are positive to the ambitious goals with the high demands of the assessment tool and its tests. As the tests recur three times per school year, the teachers feel that the collected data gives them the chance to follow students' progression. Formative assessment is, on the one hand, described as something practical and concrete, as a way of working. On the other hand, it is described as a way of thinking, an attitude, ensuring that the assessment practice does not stop at carrying out tests that are then left without further measures. Criticism is levelled against the occasional practice of using formative assessment in a more or less instrumental way including, for example, too detailed feedback from teachers (Box, 2019; Torrance, 2012). The teachers in the present study were anxious that the results of their assessments should be forward-looking and focus on the issue of "now that we have learnt this, what do we do?" Even though many of the interviewed teachers stated that the assessment support identified students in need of extra support, they were eager to point out that this was not its explicit purpose but information that came along the way. In the questionnaire, the statement is clumsily formulated and relates, according to one of the interviewees, more to identifying what future efforts are required than to identifying students.

The teaching recommendations provided by this assessment support are viewed as a good basis before the didactic choices and decisions teachers face after receiving student results on the various reading-related abilities. The didactic decisions taken after assessing students' reading abilities are not solely founded on a digit from the assessment tool that has been used but, as the teachers point out, competence is necessary to make the best of the results. It is in this context that collegial learning is highlighted as an important part of continued work on making use of the results and the information that the teachers have access to after using the assessment tool. In agreement with Timperley, Parr and Bertanees (2009), Edwards (2012), and Li (2019) the aggregate competence of the teacher team is regarded as a strength. Several respondents state the value of assessing all students in the work team by the same material, especially for offering adequate measures to students in need of extra support.

Reading development from a didactic perspective emphasizes the importance of teachers identifying students' learning needs and then forming a teaching practice that can create conditions for students to develop as readers (cf. Newton, 2007). It is, however, hard to determine what educational actions can give students this possibility. With the tool employed in this study, teachers can gain examples of exercises promoting what the individual student needs to train. Still, this concerns individual exercises and assignments, not how to plan 
teaching at large for the individual student. On the contrary, the individual teacher has to keep well informed and knowable in the didactics of reading development to be able to make a wise choice when it comes to enabling every student to develop according to his or her prerequisites. The results of the present study point in the same direction as the outcome of a study by Matre and Solheim (2015) that teacher team's assessments of student writing tend to be nuanced but more limited in their suggestions for formative feedback to students. Only to a limited extent do didactic decisions comprise the assessment information that teachers now have access to. Teachers state that even if they now know more about students' individual knowledge, it is still difficult to make didactic decisions whose consequences are effective, as is also demonstrated in a study by Blomqvist, Lindberg and Skar (2016). Some frustration emerges from the result in that teachers express that the teaching in some cases lands on some kind of middle ground or level, despite the in-depth knowledge received about every single student's needs. Time consumption and great divergence within the class are held forth as arguments for the work method chosen. As in the study by Blomqvist, Lindberg and Skar (ibid, 2016), the present results show that teachers to a very limited extent tend to use the assessment information they have formulated about students' reading ability with a view to adapting their ways of teaching reading.

\section{Conclusion}

The results show that teachers possess an explicit ambition to work according to DBDM (Schildkamp \& Kuiper, 2010; Schildkamp, Smit, \& Blossing, 2019) with a systematic analysis of the data sources existing within school, even though this has not been expressed in such terms here. In the present case, the reference is to the results generated in LegiLexi and analyzed and utilized for innovating teaching and implementing improvement measures both within the framework of the whole class but also on the basis of the individual student. A development of the aggregate assessment culture in school would effectively contribute to making more students attain the educational goals. The interview results pinpoint how important it is that the individual teachers have a good competence in the subject and knowledge of reading and writing learning which they can build on when using assessment support. Several respondents point out that the material in itself cannot replace teachers' knowledge but rather supplement it. In future research, a more practical implementation of LegiLexi could be studied, including details of how teachers actually teach based on assessments and recommendations [alt. test results], and to the extent a structured support for the organization of teaching lead to a significant increase in teaching quality.

\section{Study limitations}

One limitation of the study is that we have not observed how the school work is actually conducted, as the results are based on teacher self-report statements, in addition to a newly constructed questionnaire. As the questions are not controversial, our assumption is that the respondent teachers have given honest answers. All of them are teachers who have on their own initiative searched for the questionnaire on the homepage and then chosen to participate. Such a self- 
selected sample involves a potential bias, as the results are based on material where the respondents themselves have actively chosen to use and work with LegiLexi. Hence, they were positive to the material from the very beginning and made their own choice to work with it for at least a year, which might somewhat bias the results. There are, however, no financial incentives to respond in one way or another in this study, as all material is free to use for every teacher.

On the basis of the results, the interviews describe that teacher assessments of student writing deal with more and partly other reading ability aspects than the didactic decisions they state refer to. In contrast to Blomqvist, Lindberg and Skar (2016), who made observations that could be taken as evidence of their results, we have not done so in our study. This entails that the results of our study altogether rest on teachers' own statements and have not been set against any other type of empirical basis.

\section{References}

Bennett, R. E. (2011). Formative Assessment: A Critical Review. Assessment in Education: Principles, Policy \& Practice, 18(1), 5-25. doi.org/10.1080/0969594x.2010.513678

Black, P. \& Wiliam, D. (2009). Developing the theory of formative assessment. Educational Assessment, Evaluation and Accountability, 21(1), 5-31. doi.org/10.4135/9781446250808.n13

Blomqvist, P., Lindberg, V., \& Skar, G.B. (2016). Vad behöver eleverna undervisning i för att utveckla sitt skrivande? Förväntningsnormer och didaktiska beslut $\mathrm{i}$ svensklärares bedömningssamtal. [What do the students need in order to develop their writing? Expectation standards and didactic decisions in Swedish teachers' assessment interviews] Acta Didactica Norge, 10(1), 22-22.

Borko, H., Koellner, K., \& Jacobs, J. (2014). Examining novice teacher leaders' facilitation of mathematics professional development. Journal of Mathematical Behavior, 33, 149. doi.org/10.1016/j.jmathb.2013.11.003

Box, C. (2019). The Power of Formative Assessment. In Formative Assessment in United States Classrooms (pp. 25-48). Palgrave Macmillan, Cham. doi.org/10.1007/978-3030-03092-6_2

Brookhart, S. M. (2009). Exploring Formative Assessment. The Professional Learning Community Series. Association for Supervision and Curriculum Development. 1703 North Beauregard Street, Alexandria, VA 22311-1714. doi.org/10.4324/9781315854434

Carlson, D., Borman, G. D., \& Robinson, M. (2011). A multistate district-level cluster randomized trial of the impact of data-driven reform on reading and mathematics achievement. Educational Evaluation and Policy Analysis, 33(3), 378398. doi.org/10.3102/0162373711412765

Dunn, K. E., Airola, D. T., Lo, W. J., \& Garrison, M. (2013). Becoming data driven: The influence of teachers' sense of efficacy on concerns related to data-driven decision making. The Journal of Experimental Education, 81(2), 222-241. doi.org/10.1037/e664122011-001

Dunn, Karee E., \&Mulvenon, Sean W. (2009). A critical review of research on formative assessment: the limited scientific evidence of the impact of formative assessment in education. Practical Assessment, Research \& Evaluation,14(7), 11.

Dylan, W., \& Thompson, M. (2008). Integrating assessment with instruction: what will it take to make it work. The future of assessment: shaping teaching and learning. New York: Lawrence Erlbaum Associates. doi.org/10.4324/9781315086545-3 
Edwards, F. (2012). Learning communities for curriculum change: Key factors in an educational change process in New Zealand. Professional Development in Education,38 (1), 25-47. doi.org/10.1080/19415257.2011.592077

Ercikan, K., \& Oliveri, M. E. (2016). In search of validity evidence in support of the interpretation and use of assessments of complex constructs: Discussion of research on assessing 21st century skills. Applied Measurement in Education, 29(4), 310-318. doi.org/10.1080/08957347.2016.1209210

Harlen, W. (2005). Teachers' summative practices and assessment for learning-tensions and synergies. Curriculum Journal, 16(2), 207-223. doi.org/10.1080/09585170500136093

Hattie, J., \& Timperley, H. (2007). The power of feedback. Review of educational research, 77(1), 81-112. doi.org/10.3102/003465430298487

Heitink, M. C., Van der Kleij, F. M., Veldkamp, B. P., Schildkamp, K., \& Kippers, W. B. (2016). A systematic review of prerequisites for implementing assessment for learning in classroom practice. Educational research review, 17, 50-62. doi.org/10.1016/j.edurev.2015.12.002

Hsieh, H. F., \& Shannon, S. E. (2005). Three approaches to qualitative content analysis. Qualitative health research, 15(9), 1277-1288. doi.org/10.1177/1049732305276687

Jankowski, N. A., Timmer, J. D., Kinzie, J., \& Kuh, G. D. (2018). Assessment that matters: Trending toward practices that document authentic student learning. National Institute for Learning Outcomes Assessment. doi.org/10.1002/au.30040

Kingston, N., \& Nash, B. (2011). Formative assessment: A meta-analysis and a call for research. Educational measurement: Issues and practice, 30(4), 28-37. doi.org/10.1111/j.1745-3992.2011.00220.x

Lai, M., Wilson, A., McNaughton, S., \& Hsiao, S. (2014). Improving Achievement in Secondary Schools: Impact of a Literacy Project on Reading Comprehension and Secondary School Qualifications. Reading Research Quarterly, 49(3), 305-334. doi.org/10.1002/rrq.73

Li, M. (2019). Educational Reform and Teacher Education: A Theoretical Overview. In Understanding the Impact of INSET on Teacher Change in China (pp. 3-18). Palgrave Pivot, Singapore.

Matre, S., \& Solheim, R. (2015). Writing education and assessment in Norway: Towards shared understanding, shared language and shared responsibility. L1 Educational Studies in Language and Literature, 15, 1-33. doi.org/10.17239/11esll-2015.15.01.05

Newton, P. E. (2007). Clarifying the purposes of educational assessment. Assessment in education, 14(2), 149-170. doi.org/10.1080/09695940701478321

Schildkamp K. \& Kuiper, W. (2010). Data-informed curriculum reform: Which data, what purposes, and promoting and hindering factors. Teaching and Teacher Education, 26(3), 482-496. doi.org/10.1016/j.tate.2009.06.007

Schildkamp, K., Smit, M., \& Blossing, U. (2019). Professional development in the use of data: From data to knowledge in data teams. Scandinavian Journal of Educational Research, 63(3), 393-411. doi.org/10.1080/00313831.2017.1376350

Schildkamp, K, \& Teddlie, C. (2008). School performance feedback systems in the USA and in the Netherlands: A Comparison. Educational Research and Evaluation, 14(3), 255-282. doi.org/10.1080/13803610802048874

Schneider, M. C., \& Randel, B. (2010). Research on characteristics of effective professional development programs for enhancing educators' skills in formative assessment. Handbook of formative assessment, 251-276.

Swedish National Agency for Education. (2017). Curriculum for the compulsory school, preschool class and the recreation center 2017. Stockholm: Skolverket. Sweden. 
Tait-McCutcheon, S., \& Drake, M. (2016). If the jacket fits: A metaphor for teacher professional learning and development. Teaching and Teacher Education, 55, 1-12. doi.org/10.1016/j.tate.2015.12.005

Timperley, H. \& Alton-Lee, A. (2008). Reframing teacher professional learning: An alternative policy approach to strengthening valued outcomes for diverse learners. Review of Research in Education, 32(1), 328-369. doi.org/10.3102/0091732x07308968

Timperley, H. S., Parr, J. M., \& Bertanees, C. (2009). Promoting professional inquiry for improved outcomes for students in New Zealand. Professional development in education, 35(2), 227-245. doi.org/10.1080/13674580802550094

Torrance, H. (2012). Formative assessment at the crossroads: Conformative, deformative and transformative assessment. Oxford Review of Education, 38(3), 323-342. doi.org/10.1080/03054985.2012.689693

Van der Kleij, Fabienne M. et al., (2015). Integrating Data-Based Decision Making, Assessment for learning and diagnostic testing in formative assessment. Assessment in Education: Principles, Policy \& Practice, 22(3), 324-343. doi.org/10.1080/0969594x.2014.999024

Wiliam, D. (2011). What is assessment for learning?. Studies in educational evaluation, 37(1), 3-14. doi.org/10.1016/j.stueduc.2011.03.001 